\section{STANDING ON THE SHOULDERS OF GIANTS...}

In this month's airwaves, we salute those titans of medicine who have made present day advances in medicine possible.

\section{BACK TO BLACK}

Almost 40 years ago, the Black Report demonstrated that health inequalities were widespread, despite the fact that healthcare was (and is) free at the point of delivery in the UK. Sir Douglas Black provided evidence that the root cause of these health inequalities was economic: wealthier means healthier. Fast forward to 2019 and this month's issue of Thorax (see page 51), where Belot et al explore why some patients with early stage lung cancer have surgery and some do not. They found that comorbidities (congestive heart failure, cerebrovascular disease and COPD) may explain why some patients do not have surgery. Age and sex also play a role. However, even when these factors are taken into account, individuals who suffer greater levels of deprivation had less chance of receiving surgery for early stage lung cancer. The 'Inverse Care Law' (1971) proposed by the late Julian TudorHart still applies.

\section{EIGHTY YEARS OF CYSTIC FIBROSIS RESEARCH}

Dorothy Andersen, an American pathologist and paediatrician, first described 'cystic fibrosis of the pancreas' in 1938. A decade later, she published one of the first reports of the natural history of the disease and the response to treatment (Pediatr 1949; 3 (4): 406-17). In this paper, she describes the microbiological basis of early lung infection, 'Cultures taken early in the course of the disease grow Staph. aureus hemolyticus in nearly every case...'. One possible source of such infections with Staphylococcus aureus is explored in Thorax this month (see page 87). Wood et al describe how S. aureus is aerosolised during coughing. They studied 30 people with $\mathrm{CF}$, in a validated cough protocol, using a cascade impactor. They found that cough aerosols can travel $4 \mathrm{~m}$ and organisms remain viable within droplet nuclei for up to $45 \mathrm{~min}$. This provides some underpinning evidence for person-to-person spread of infection. In 1949, Dorothy Andersen described progress during the first decade of CF research: '... a considerable body of knowledge in regard to the disease has been accumulated by the efforts of many workers in this and other lands.' Eighty years after her discovery of CF, researchers in the USA and 'other lands' continue to improve the duration and quality of life for people with $\mathrm{CF}$.

\section{WHAT HAVE THE WORMS EVER DONE FOR US?}

In the 1970's Sydney Brenner, John Sulston and Robert Horovitz discovered the role of genes that promoted cell death in the Caenorhabditis elegans nematode, the nuc1 , ced-3 and ced-4 genes. This system of programmed cell death was called apoptosis and lead to the joint award of the Nobel Prize to Brenner, Sulston and Horovitz in 2002. In 1989, Trauth et al first described the possibility of manipulating the first apoptosis signal (Fas) receptor to promote apoptosis. Since then over 11000 publications have manipulated this receptor in various experimental and therapeutic settings. Herrero et al (see page 69) show that Fas activation of epithelial cells in the lung leads to increased alveolar permeability through effects on tight junctions both in vitro and in vivo and this occurs before apoptosis. Inhibiting caspase-3 was able to prevent this permeability and could offer a new therapeutic option in acute lung injury (ALI). So apart from helping us develop strategies to treat cancer and now ALI, what have the worms ever done for us?

\section{THE FATHER OF TRANSPLANTATION}

In 1912, Alexis Carrel, a French Surgeon, was awarded the Nobel Prize for Physiology and Medicine for pioneering surgical techniques. He also performed the first experimental transplants, which due to a lack of immunological understanding at the time, did not have great results. In 1960, Sir Peter Medawar was awarded the Nobel Prize, with Sir Mac Burnett, for discovery of acquired immunological tolerance, which opened the door for organ transplantation. Only 23 years later, Joel Cooper performed the first lung transplantation in Toronto General Hospital on 7 November 1983 and now we regard lung transplants as 'curative' procedures for life-limiting diseases. However, there are many more people in need of transplants than available organs. Kourliouros et al (see page 60) address the factors that affect waiting list mortality. Patients with COPD were more likely to receive a transplant within 3 years, whereas patients with IPF were more likely to die on the transplant waiting list. Similarly, taller patients were more likely to receive a transplant, whereas patients with blood group $\mathrm{O}$ had the highest waiting list mortality. The authors hope that the restructuring donor allocation in the UK will help reduce these discrepancies, however, as the father of transplantation reminds us 'the intensity of the conviction that a hypothesis is true has no bearing on whether it is true or not', which we would propose is sound advice to all scientists, so we need to wait and see what the data tell us.

\section{SIR BEDEVERE THE WISE}

It was only recently in 2012 that Sir John Gurdon and Shinya Yamanaka shared the Nobel Prize for their pioneering work on stem cells and stem cell therapy remains the Holy Grail of medicine. It is therefore a little surprising to discover that the first reports of stem cells biology emanate from the mid-19th century when Goujon in 1869 , then MacEwen in 1881, described the osteogenic potential of transplanted bone marrow giving rise to the first example of mesenchymal stem cells (MSCs). In this issue of Thorax, Park et al (see page 43) describe the development of microvesicles (MVs) secreted as by MSCs as a potential therapy for ALI. Administration of MSC MV to human ex vivo model of bacterial pneumonia increased alveolar fluid clearance and reduced protein permeability and bacterial load in the injured alveolus. So maybe the answer to the Holy Grail is to use stem cells as Trojan Rabbit?

\section{MIND GAMES}

In 1979, following training under Buddhist teacher Thich Nhat Hanh, Jon Kabat-Zinn founded the mindfulness-based stress reduction programme at the University of Massachusetts to treat the chronically ill. He used this ancient meditation practice to alleviate the suffering of his patients. The same approach has been adopted by Cox et al (see page 33 ) with a focus of combining the old with the new. The investigators performed a feasibility study of the impact of mindfulness training programmes, delivered by a mobile app, by telephone or a face-to-face education programme for survivors of critical illness. In a 3-month trial, the mobile mindfulness app was shown to be feasible, acceptable and usable and indeed had a similar impact on psychological distress and physical symptoms as a therapist-led programme. It sounds like we all need a bit of mindfulness training and now it can be delivered by your smartphone!

(c) Author(s) (or their employer(s)) 2019. No commercial re-use. See rights and permissions. Published by BMJ. 